\title{
Subependymal heterotopia: a distinct neuronal migration disorder associated with epilepsy
}

\author{
A A Raymond, D R Fish, J M Stevens, S M Sisodiya, N Alsanjari, S D Shorvon
}

\begin{abstract}
Subependymal heterotopia has recently been recognised as a cause of epilepsy, but the clinical and investigational features have not been fully described. The clinical, psychometric, imaging, and electroencephalographic features of 13 adult patients with subependymal heterotopia and epilepsy have been reviewed. Age at seizure onset ranged from 18 months to 20 years (median 13 years). There were significantly more female (12) than male (1) patients $(p<0.01)$. Diagnosis of subependymal heterotopia was made by MRI in 11 patients and CT in two. The heterotopic grey matter was nodular in 11 patients and diffuse in two; bilateral in eight and unilateral in five. There were significantly more patients with predominant right than left cerebral hemisphere involvement $(p<0.01)$. The most commonly involved site was the occipital horn of the lateral ventricles (10 of 13 patients). Eleven patients presented with partial epilepsy, 10 of whom also had secondarily generalised seizures. The clinical description of the seizures often suggested either an occipital (four patients) or temporal (five patients) onset. Two patients presented with absence attacks without clear focal features. Patients demonstrated normal early milestones (12 of 13 patients), including normal motor development (all patients) and average or above average intelligence (10 of 13 patients). An EEG examination showed normal background activity in all but two patients, one of whom had large intracranial
\end{abstract} haematomas. Epileptiform activity was usually widespread (10 of 13 patients) and in three patients, there was generalised 3$\mathrm{Hz}$ spike and wave activity that had previously led to an erroneous diagnosis of concomitant primary generalised epilepsy. Onset of epilepsy in the second decade of life, normal developmental milestones and intelligence, and the finding of an overwhelming female preponderance differentiates subependymal heterotopia from other cortical dysgeneses. The female preponderance supports the importance of the $X$ chromosome and sex steroids in the maturation and development of the cerebral cortex.

(F Neurol Neurosurg Psychiatry 1994;57:1195-1202)
Migration of neuroblasts from the periventricular germinal centres occurs maximally between the 7 th and 16 th gestational weeks, although it is known to continue for several months postnatally. ${ }^{1}$ Neuroblasts migrate centrifugally along radial glial fibres towards the pial surface. They come to rest in the cortical plate after detaching themselves from the fibres, in an inside out fashion, with more recent arrivals lying more superficial to earlier ones: ${ }^{23}$ More recently, there is evidence that there is also lateral dispersion of neuroblasts during migration. ${ }^{4}$

The causes of neuronal migration disorders may be both genetic and maternal/environmental. ${ }^{5} \mathrm{~A}$ defect in the radial glial fibres has been proposed to be the underlying mechanism for migrational arrest in many of the neuronal migration disorders. ${ }^{6}$ Morphologically, the disorders appear either as collections of neurons in abnormal locations (grey matter heterotopia) or disordered cortical lamination and gyration (for example, macrogyria, polymicrogyria).

Subependymal heterotopia seems to be a well defined and discrete entity-namely, heterotopic grey matter situated adjacent to the wall of the lateral ventricles, ${ }^{6}$ just beneath and abutting the ependyma. Sometimes also termed "periventricular heterotopia", subependymal heterotopia may represent either clusters of neurons that have been arrested in migration, or failure of programmed cell death of collections of neuroblasts within the periventricular germinal matrix. Owing to its location and association with normal overlying cortex, the defect in the radial glial fibres is likely to be proximal and likely to have occurred after most neurons have migrated to the cortical plate. ${ }^{7}$ There is a dearth of literature on "pure" cases of subependymal heterotopia. $^{7-15}$ Many reports either lump all the heterotopias together, or the subependymal heterotopias with other cortical dysgeneses. Certain features of subependymal heterotopia not previously described have become apparent, however, and are in our opinion, sufficient to make it an entity distinct from other neuronal migration disorders. The clinical, EEG, psychometric, and neuroimaging features of 13 adult patients with epilepsy are described and the English medical literature on similar cases is reviewed.

Patients and methods

Of 69 adult patients with epilepsy and cortical dysgenesis diagnosed on CT or MRI at our 
Table 1 Clinical features and summary of neuroimaging findings in 13 adults with epilepsy and subependymal heterotopia

\begin{tabular}{|c|c|c|c|c|c|}
\hline Patient & $\begin{array}{l}\text { Age at Diagnosis/ } \\
\text { seizure onset } \\
(y) / \text { sex }\end{array}$ & $\begin{array}{l}\text { No of miscarriages } \\
\text { (Mo:P)/ } \\
\text { siblings }(S: B)\end{array}$ & $I Q$ & Location of subependymal heterotopia & Seizure description \\
\hline 1 & $27 / 12 / \mathrm{F}$ & 2:0/0:0 & $\begin{array}{l}\text { VIQ 112; } \\
\text { PIQ } 107\end{array}$ & $\begin{array}{l}\text { BL; large nodules; inferolateral margins } \\
\text { trigones, extending to temporal horn on } \mathrm{R} \text {. }\end{array}$ & $\begin{array}{l}\text { Becomes vacant and unresponsive; orofacial and } \\
\text { manual automatisms; } \pm \text { clonic movements } R \text { hand; } \\
\text { dysphasic and amnesic afterwards. }\end{array}$ \\
\hline 2 & $19 / 11 / \mathrm{F}$ & NA & NP & $\begin{array}{l}\text { BL; small nodules; superolateral margins } \\
\text { frontal horns }(R>L) \text {. }\end{array}$ & $\begin{array}{l}\text { Feels as if looking through a dark tunnel with } \\
\text { approaching flashing lights/vague feeling in head; } \\
\text { head turns to L; always progresses to SGTCS. }\end{array}$ \\
\hline 3 & $29 / 20 / \mathrm{F}$ & $0: 0 / 2: 1^{\star}$ & FSIQ 73 & $\begin{array}{l}\text { BL; large nodules; lateral margins body/ } \\
\text { anterior horns LV (CT only). }\end{array}$ & $\begin{array}{l}\text { (i) Brief absences. (ii) SGTCS with predominant } \\
\text { L sided twitching and transient post-ictal } \\
\text { L hemiparesis. }\end{array}$ \\
\hline 4 & $29 / 16 / F$ & $0: 1 / 2: 0$ & NP & UL; 1 large nodule; medial margin $\mathrm{R}$ trigone. & $\begin{array}{l}\text { Jerking of L hand without LOC; } \pm \text { SGTCS } \\
\text { (mainly nocturnal). }\end{array}$ \\
\hline 5 & $26 / 19 / \mathrm{F}$ & NA & NP & $\begin{array}{l}\text { UL; diffuse; lateral margin R trigone/posterior } \\
\text { body LV. }\end{array}$ & $\begin{array}{l}\text { Feels as if "on other side" and looking through } \\
\text { frosted glass; remains responsive and capable of } \\
\text { normal speech; } \pm \text { SGTCS. }\end{array}$ \\
\hline 6 & $22 / 15 / F$ & $0: 0 / 2: 1$ & FSIQ 119 & $\begin{array}{l}\text { BL; large nodules; lateral margins body/ } \\
\text { trigone LV. }\end{array}$ & $\begin{array}{l}\text { Dèjá vu feeling; becomes unresponsive; oral } / \text { manual } \\
\text { automatisms; } \pm \text { SGTCS. }\end{array}$ \\
\hline 7 & $34 / 13 / F$ & 0:0/0:0 & NP & $\begin{array}{l}\text { BL; large nodules; inferolateral margins } \\
\text { trigones }(R>L) \text {. }\end{array}$ & $\begin{array}{l}\text { (i) Brief absences; } \pm \text { SGTCS, (ii) dèjá vu feeling; } \\
\text { abrupt mood changes and altered perception of } \\
\text { surroundings. }\end{array}$ \\
\hline 8 & $31 / 17 / F$ & 0:0/0:2 & NP & $\begin{array}{l}\text { BL; diffuse; lateral/inferolateral margins } \\
\text { trigones/temporal horns }(R>L) \text {. }\end{array}$ & $\begin{array}{l}\text { Objects become distorted or change colour; becomes } \\
\text { unresponsive; } \pm \text { motor automatisms; } \pm \text { SGTCS. }\end{array}$ \\
\hline 9 & $31 / 3 / F$ & $0: 3 / 0: 1$ & $\begin{array}{l}\text { VIQ 93; } \\
\text { PIQ 78; } \\
\text { FSIQ } 85\end{array}$ & $\begin{array}{l}\text { BL; large nodules; lateral/superior margins } \\
\text { trigones, lateral/inferior margins temporal } \\
\text { horns and lateral margins frontal horns }(\mathrm{L}>\mathrm{R}) \text {. }\end{array}$ & $\begin{array}{l}\text { (i) Sees light flashing in a distance in } R \text { eye; stares } \\
\text { and becomes unresponsive; manual automatisms; } \\
\pm \text { SGTCS. (ii) becomes unresponsive; violent } \\
\text { shaking of } R \text { limbs, then all four limbs. } t\end{array}$ \\
\hline 10 & 21/7/M & NA & FSIQ 69 & $\begin{array}{l}\text { UL; } 1 \text { small nodule; inferolateral margin } R \\
\text { trigone. }\end{array}$ & $\begin{array}{l}\text { (i) Brief absences; } \pm \text { SGTCS. (ii) becomes quiet; } \\
\text { shouts for help; arms raised and moves about; } \\
\text { shakes all } 4 \text { limbs. } \neq\end{array}$ \\
\hline 11 & $25 / 1 \quad 1 / 2 / F$ & NA & $\begin{array}{l}\text { VIQ } 97 \\
\text { PIQ } 86 \\
\text { FSIQ } 92\end{array}$ & $\begin{array}{l}\text { BL; small nodules; superior margins } \\
\text { trigones/occipital horns }(R>L) \text {. }\end{array}$ & $\begin{array}{l} \pm \text { Aura of an urge to urinate; becomes unresponsive; } \\
\text { dystonic posturing of } R \text { hand; orofacial automatisms; } \\
\text { dysphasic afterwards; } \pm \text { SGTCS. }\end{array}$ \\
\hline 12 & $31 / 20 / \mathrm{F}$ & NA/ $1: 0 \$$ & NP & UL; large nodules; lateral margin R trigone.\| & $\begin{array}{l}\text { Becomes unresponsive, } \mathrm{R} \text { side becomes weak; } \\
\text { manual automatisms; incontinent of urine; confused } \\
\text { afterwards. }\end{array}$ \\
\hline 13 & $28 / 1 \quad 1 / 2 / F$ & $1: 0 / 0: 0$ & NP & $\begin{array}{l}\text { UL; large nodules; lateral margin } \mathrm{R} \text { trigone } \\
\text { (CT only). }\end{array}$ & $\begin{array}{l} \pm \text { Aura of "fizziness" in head; ringing in ears; white } \\
\text { spots cross visual fields; becomes unresponsive and } \\
\text { stares into space; confused afterwards; } \pm \text { SGTCS. }\end{array}$ \\
\hline
\end{tabular}

Mo = mother; P = patient; B = brothers; S = sisters; VIQ = verbal IQ; PIQ = performance IQ; FSIQ = full-scale IQ; SGTCS = secondarily generalised tonicclonic seizure; $\mathrm{BL}=$ bilateral; $\mathrm{UL}=$ unilateral; $\mathrm{LV}=$ lateral ventricle; ${ }^{\star} \mathrm{a}$ twin brother and two older sisters who are also twins; fassessed to be pseudoseizures on video-EEG telemetry; fonset after head injury at age 16; \$twin sister died at birth, cause unknown; \|additional subcortical white matter nodular heterotopia; $\mathrm{NA}=$ not available; $\mathrm{NP}=$ not performed, but $\mathrm{IQ}$ assessed to be average or above average from profession/interaction with medical staff.

centre, 13 had subependymal heterotopia and were included in the study. Age at diagnosis ranged from 19 to 34 years (median 27 years). All patients attended either the National Hospital for Neurology and Neurosurgery or the Chalfont Centre for Epilepsy. Clinical details, including age at seizure onset, seizure description, antenatal and birth history, developmental milestones, family history, neuropsychological assessment, and physical signs were obtained retrospectively by reviewing their medical records (table 1). Two patients proceeded to surgery and their pathological slides were reviewed by one of us (N A).

Diagnosis of subependymal heterotopia was based on neuroimaging. All patients had CT and 11 also had MRI. In nine patients, MRI was performed on a 1.5 Tesla GE Signa unit (GE Medical Systems, Milwaukee, USA). Five of these patients also had $1.5 \mathrm{~mm}$ contiguous coronal slices using a 35/5/1 (TR/TE/NX) pulse sequence, flip angle $35^{\circ}$, and matrix size $256 \times 128$, which permitted multiplanar reformatting with an independent console. The hippocampal volumes of these five patients were also measured by the method described by Cook et al. ${ }^{16}$ Of the remaining patients, one was scanned on a 1.5 Tesla Siemens Magnetom unit, and the other on a 0.26 Tesla Picker International system.

The EEGs were recorded on a minimum of 16 channels with the 10-20 international system of electrode placement, and incorporated hyperventilation and photic stimulation.
Statistical analysis was performed by the two tailed binomial test and a $\mathrm{p}$ value $\leqslant 0.05$ was deemed significant.

\section{Results}

CLINICAL FEATURES (TABLE 1)

There were significantly more female $(\mathbf{n}=$ 12) than male $(n=1)$ patients $(p<0.01)$. Age at seizure onset ranged from 18 months to 20 years (median 13 years). Nine of 13 patients developed seizures between the ages of 11 and 20 years. Family histories were unremarkable for epilepsy and tuberous sclerosis. Further analysis in nine patients showed a total of 12 siblings (seven females and five males), none of whom have epilepsy, although one patient (4) has two sisters with undiagnosed early morning jerks. Three patients had no siblings. To date, none of our patients' relatives have had brain scans.

A personal or maternal history of spontaneous abortions was present in four of eight patients in whom this information was available (table 1); the mother of one of these patients (1) had also had an ectopic pregnancy. A history of prenatal or perinatal problems was present in eight patients - namely, preterm delivery ( $<37$ weeks) in four (patients $2,3,9,12)$, post-term ( $>40$ weeks) delivery in two $(10,13)$, pre-eclampsia in two $(9,13)$, forceps delivery in two $(1,13)$, twin pregnancies in two $(3,12)$, and pyrexia shortly after birth in one (6). Patient 6 also had a persistent 
ductus arteriosus that was surgically repaired at age $\mathbf{3 0}$ months.

Delayed early developmental milestones were reported in only one patient (10). The product of a prolonged labour induced at 42 weeks of gestation, he sat and walked at 12 and 30 months respectively, and also manifested aggressive and compulsive behaviour from the age of 13. At the age of 16 he had a serious head injury from a fall, resulting in haematomas in the right frontal and parietal lobes and alteration to his seizure pattern.

Childhood febrile convulsions were reported in two patients $(2,11)$. One of these patients ${ }^{11}$ had a prolonged febrile convulsion (>20 minutes) at 10 months and showed MRI and subsequently pathological evidence, of concomitant hippocampal sclerosis (see later).

In all patients, the seizures were medically refractory, in as much as they either interfered with employment or lifestyles or occurred at least once a month and were resistant to at least two consecutive antiepileptic drugs. Seven patients $(1,3,7,9,10,11,12)$ had additional descriptions of their habitual seizures from video-EEG telemetry. The clinical features of the seizures were heterogeneous, suggesting an extratemporal onset in six patients and a temporal onset in five, and were generalised at the onset in the remaining two (table 1). Ten of the 11 patients with partial epilepsy had secondarily generalised seizures as well. Of the extratemporal cases, four complained of visual auras suggesting an occipital onset: flashing lights in two, "white spots" in one, and distortion of shape and colour in another. In one patient (2), the seizures always became secondarily generalised, and in two patients $(3,13)$, there was rapid loss of awareness, but progression to secondary generalisation was rare (< one every two years). In the fourth patient (9), prominent manual automatisms such as fiddling with clothing ensued, suggesting spread to temporal structures. Localisation of seizure onset was less clear in the other two patients with extratemporal epilepsy but the clinical features suggested possible onset in the motor cortex, namely, clonic movements of the left hand in one patient (4) and rapid weakness of the right side in the other (12). Features suggesting a temporal onset in the other five patients with partial epilepsy included orofa$\mathrm{cial} /$ manual automatisms, psychic/experiential phenomena, or both, and in one patient (11), clear dystonic posturing of the contralateral arm. The two patients $(2,10)$ without focal onsets had only brief absences which at times, progressed to generalised tonic-clonic convulsions. Three patients $(3,9,10)$ had coexistent pseudoseizures documented on video-telemetry. In one of these patients (10), pseudoseizures were the dominant seizure type. A history of convulsive status epilepticus was present in three of 12 patients $(3,7,9)$, although pseudostatus was suspected in one (3).

Physical examination did not show any permanent neurological deficits. Examination of the skin showed two café au lait spots in patient 8 and one in patient 5 , but no other stigmata of tuberous sclerosis, although not all were examined with UV light. Concomitant congenital abnormalities were present in two patients: a persistent ductus arteriosus (patient 6) and shortened terminal phalanges of the thumbs and great toes (patient 9). Patient 10 was a normal male phenotypically, although we have not been able to perform chromosomal analyses on him.

Results of formal psychometric tests were available for five patients. Only two patients had an IQ $<80$, one of whom (10) was assessed only after he had had extensive intracerebral haematomas from a fall. The intellectual capacity of the other patients was judged by their occupations, educational achievements, and interaction with medical staff, and was generally average or above average.

Two patients $(1,11)$ have had anterior temporal lobectomies after a diagnosis of concomitant hippocampal sclerosis based on clinical, EEG, and neuroimaging data (see earlier). In both patients, the resection did not include the heterotopic tissue, this being confirmed by postoperative MRI. Pathological examination confirmed the diagnosis of hippocampal sclerosis, and in patient 11 , there was neuronal ectopia in the subcortical white matter (or "microdysgenesis", as defined by Meencke and Veith ${ }^{16}$ ) and splitting of the dentate fascia. Only patient 11 had a definite history of childhood febrile convulsions. Patient 1 has been followed up for eight months after operation and has had complete freedom from seizures and auras. In the 10 months of follow up, patient 11 has had only one seizure, similar to her preoperative seizures, representing a greater than $90 \%$ reduction in seizure frequency.

NEUROIMAGING FINDINGS (TABLE 1)

The brain CT scans of four patients were available for review. The heterotopic tissue appeared either as broad bands lying along the lateral walls of the lateral ventricles (patient 5) or multiple nodules protruding into the lateral ventricles (patients $3,6,13$ ). These lesions had densities similar to that of the cortical ribbon and calcification was not seen (fig 1). Reports for CT were available for eight of the nine remaining patients; only one reported subependymal heterotopia.

The anatomical delineation of the heterotopic tissue by MRI was excellent: only the lateral ventricles were involved, and the heterotopic tissue was isointense to grey matter on all sequences. The distribution of the subependymal heterotopia was bilateral in eight and unilateral in five patients. When unilateral, the heterotopic tissue was always on the right. When bilateral, it was either symmetric or more extensive on the right, except for patient 9, where it was more extensive on the left. The right compared to left sided predominance was statistically significant $(p<0 \cdot 01)$. Patient 12 had evidence of additional large nodules of heterotopic grey 
Figure 1 Axial CT image showing multiple subependymal heterotopic nodules (arrows).

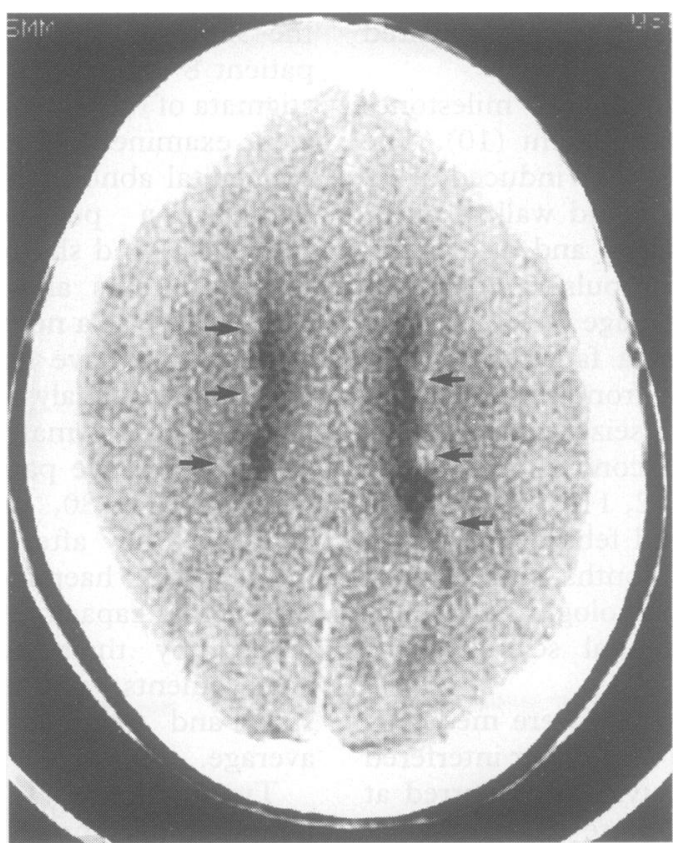

Figure 2 Coronal image from a volumetric acquisition with strong $T 1$ weighting (see text for details), showing bilateral nodular subependymal heterotopia projecting slightly into each occipital horn from the inferolateral aspect.

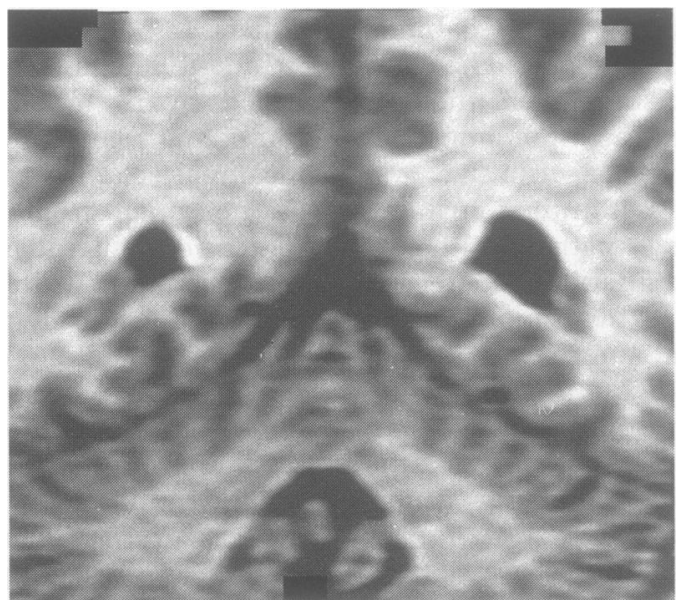

Figure 3 Coronal image from a volumetric acquisition with strong $T 1$ weighting (see text for details), showing bilateral diffuse subependymal heterotopia around the lateral and inferior margins of the atrium of each lateral ventricle.

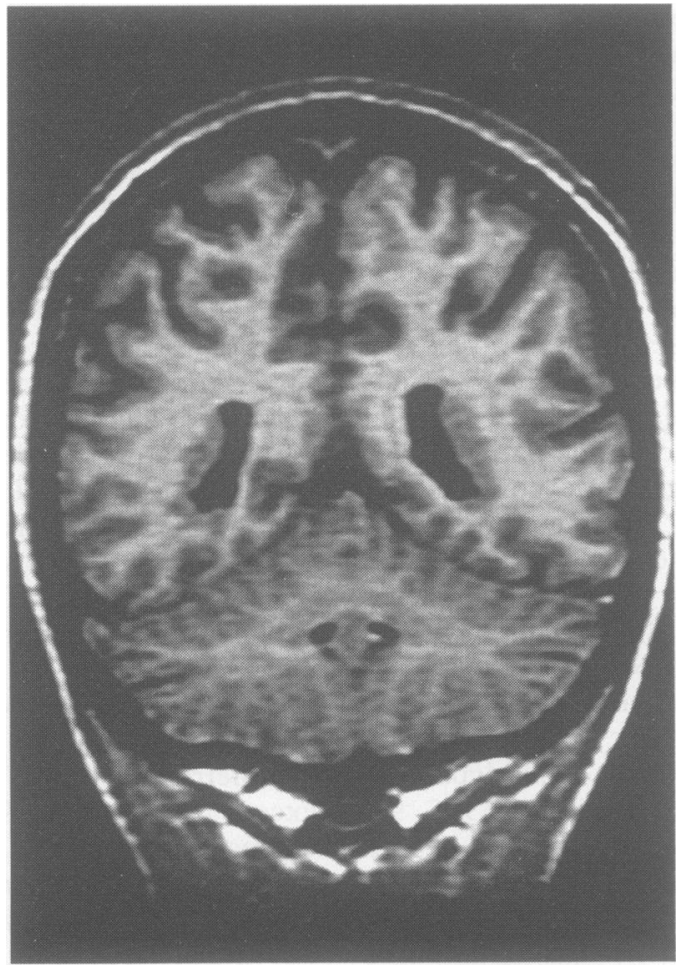

matter in the subcortical white matter adjacent to the subependymal heterotopia as well as expansion of the ipsilateral temporal lobe.

Like CT, on MRI, the subependymal heterotopia appeared either as solitary nodules (nodular subependymal heterotopia, fig 2) projecting into the ventricles (nine patients) or diffuse broad bands (diffuse subependymal heterotopia, fig 3) lining the ventricles (two patients). The nodules were either rounded or ovoid. We have arbitrarily classified the nodules as small, when they were $<5 \mathrm{~mm}$ in size, or large (table 1). The diffuse bands had an irregular and "lumpy" outline and seemed to contain multiple nodules which had "coalesced". Whether the heterotopic grey matter was nodular or diffuse did not seem to affect its unilaterality or bilaterality or seizure frequency.

The trigones and occipital horns were the most commonly involved sites (10 patients). In one patient (2), MRI showed only one small nodule lying adjacent to the superolateral margins of each frontal horn. The other patient (3) without evidence of peritrigonal involvement had CT only (see earlier), and thus could have had more extensive subependymal heterotopia. In two patients, the subependymal heterotopia extended forwards from the trigones to the body of the lateral ventricles, and in four patients, to the temporal horns. The frontal horns were involved in four patients. When the temporal horns were involved, the subependymal heterotopia sometimes abutted or displaced the hippocampal formation (patient 9, fig 4).

None of the patients exhibited additional gyral abnormalities or more extensive areas of cortical dysgenesis. Hippocampal volume measurements in five patients showed symmetric hippocampi in three $(4,7,8)$ and asymmetric hippocampi in the remaining two $(1,11)$. Patient 1 had a smaller right hippocampus with a right to left ratio of 0.84 and patient 11 a smaller left hippocampus with a left to right ratio of $0 \cdot 65$. Both patients had bilateral subependymal heterotopia, with more extensive involvement on the right. In patient 1 , the subependymal heterotopia extended to the temporal horn adjacent to the smaller hippocampus but did not abut the ipsilateral hippocampus.

\section{EEG FINDINGS}

Unilateral subependymal heterotopia $(n=5)$

Only two patients showed focal and lateralised EEG abnormalities. These were runs of high amplitude, $2-\mathrm{Hz}$ to $3-\mathrm{Hz}$ activity, and frequent spike and slow wave activity in the hemisphere containing the subependymal heterotopia, maximal in amplitude and frequency anterior to the abnormality (patient 12), and frequent focal sharp waves in the right occipital region in addition to a mild generalised background abnormality (patient 13, fig 5).

Of the remaining three patients, one showed a generalised background abnormality only, with loss of the alpha rhythm and an excess of slow activity (patient 10), one showed generalised $3-\mathrm{Hz}$ spike and wave 
Figure 4 A pair of nearly contiguous images from a multislice acquisition using an inversion recovery sequence (TR 2000/TI 700/TE 18) showing nodular subependymal heterotopia, involving the lateral aspect and floor of each temporal horn (far larger on the left), and the lateral margin of the right frontal horn (arrows). Note the unusual configuration of each hippocampus.

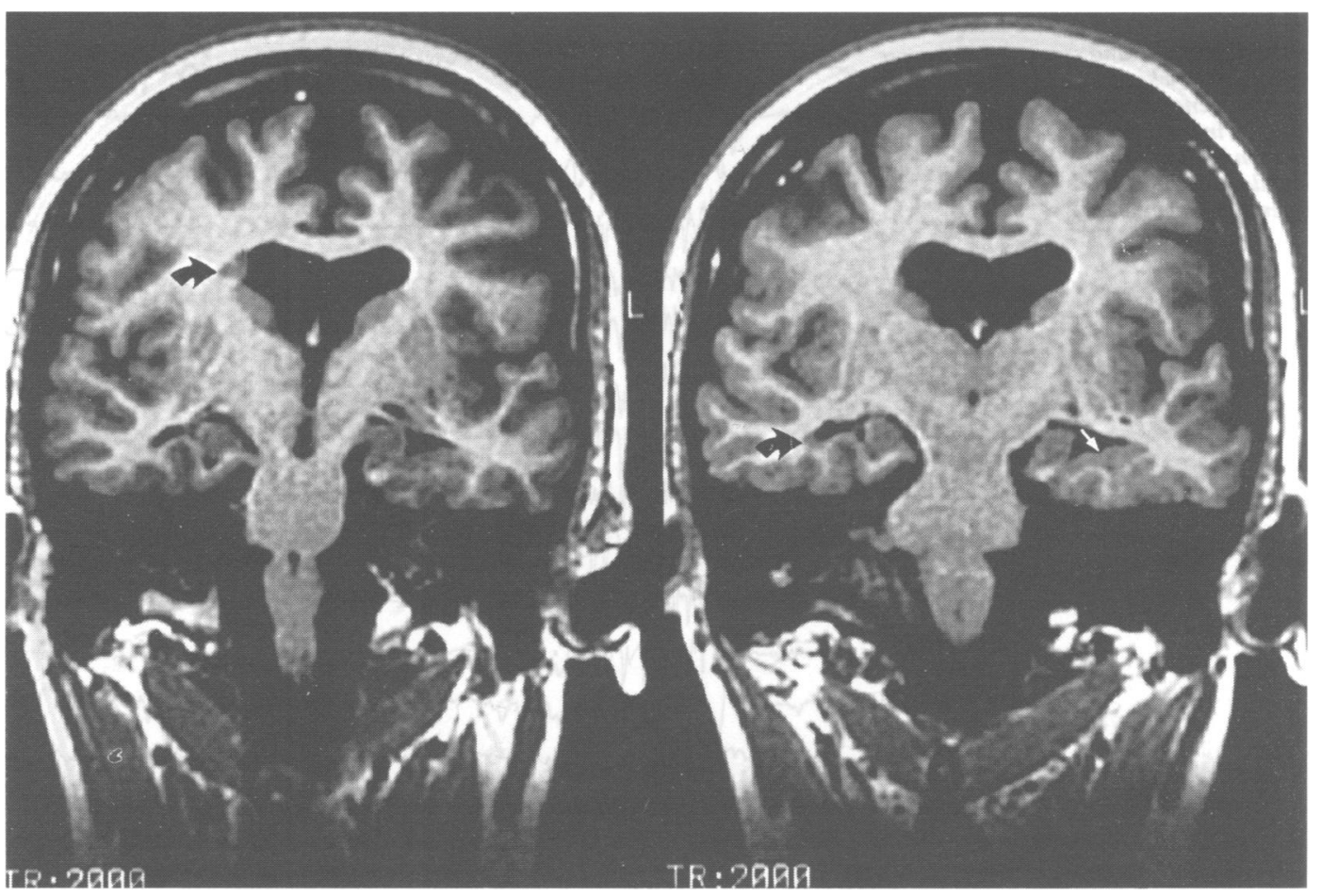

activity mimicking primary generalised epilepsy (patient 4) and finally, one showed an unusual burst of bilateral theta activity during overbreathing, which was unaccompanied by a change in clinical behaviour. Photosensitivity was not seen in any case.

Bilateral subependymal heterotopia $(n=8)$

The alpha rhythm was preserved in all patients, but in two patients $(6,7)$, there was also a generalised excess of slow activity.
There were unequivocal epileptiform abnormalities in all patients. Two patients $(2,7)$ showed generalised $3-\mathrm{Hz}$ to $4-\mathrm{Hz}$ spike and wave activity mimicking primary generalised epilepsy (fig 6); in one (2), this was the only abnormality and in the other, there was additional focal right temporal spike and slow wave activity. In the remaining patients, there were focal spikes, sharp waves, or sharp and slow wave activity, distributed either independently or synchronously in both temporal lobes $(1,11)$, or widely in one hemisphere, in
Figure 5 A monopolar EEG recording (using average reference) showing focal sharp waves in the right occipital region (O2) and a mild generalised background abnormality. This patient's CT (patient 13) showed nodular subependymal heterotopia projecting into the trigone of the right lateral ventricle. Channel 16 (O1), not displayed here, did not show similar sharp waves.

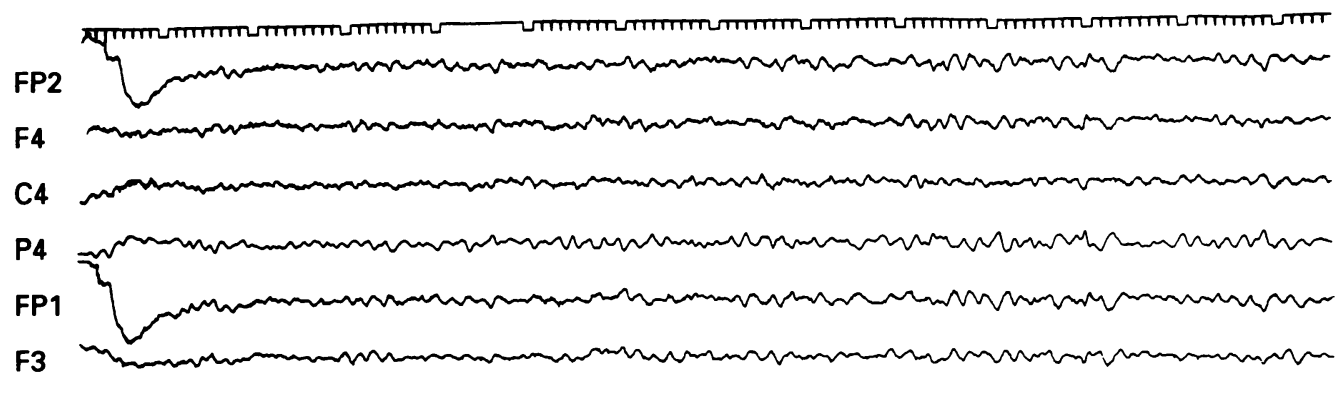

C3

P3

F8

T4

T6

$\mathrm{O} 2$

F7

T3

T5 
Figure 6 Bursts of generalised spike and wave activity mimicking primary generalised epilepsy in a 34 year old woman with bilateral nodular subependymal heterotopia (patient 7).

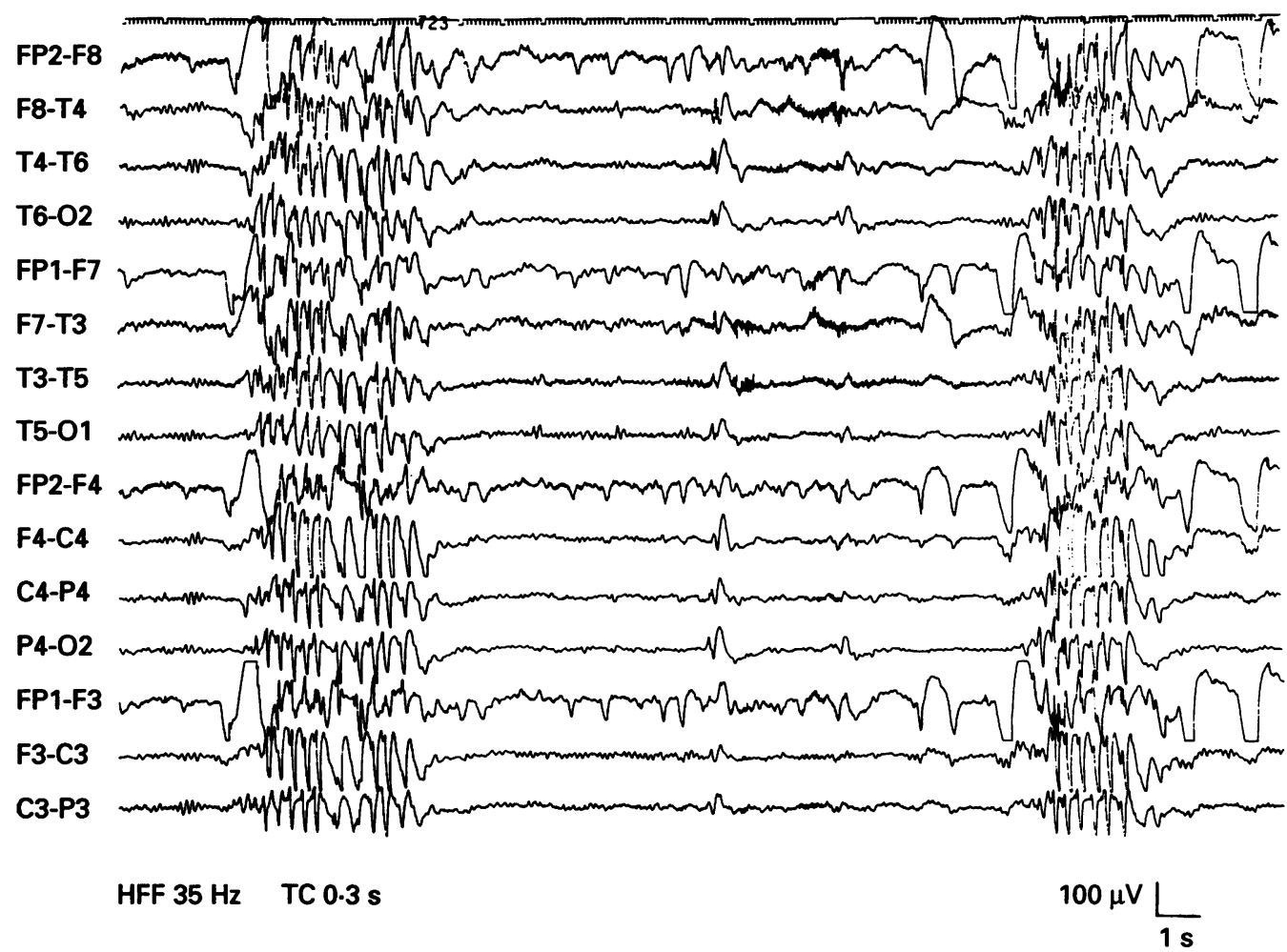

the frontocentrotemporal region $(3,6,9)$. In the remaining patient (8), there were bilateral independent spike and wave complexes without any clear localisation. Photosensitivity was not seen in any case.

\section{Discussion}

Grey matter heterotopias are clusters of neurons thought to have been arrested during migration. They appear as nodules or bands, and may be subpial, subcortical (in the centrum semiovale), or subependymal in location. ${ }^{6}$ These subdivisions are to a certain extent artificial, in that they may be found in association with each other or coexist with other cortical dysgeneses (for example, macrogyria, polymicrogyria, and schizencephaly). When in a subependymal location, the nodules may either be discrete or may be close together to form irregular or "lumpy" bands adjacent to the lateral ventricles, often bilaterally and symmetrically. We consider, however, that the term "band heterotopia" as used by some authors ${ }^{9}$ to describe the latter, is misleading and should be reserved only for subcortical bands of heterotopic grey matter in the centrum semiovale, as described previously as a specific entity. ${ }^{18} 19$ We prefer the terms nodular and diffuse subependymal heterotopia. Overall, subependymal heterotopia is more likely to be bilateral than unilateral (tables 1 and 2). Also, it is our experience as well as the experience of some other authors ${ }^{13}$ that subependymal heterotopia is the commonest form of grey matter heterotopia, at least in the adult population, based on imaging alone.

A defect involving the radial glial fibres, which act as guides for the migration of neurons has been proposed to be the mechanism for subependymal heterotopia. This defect

Table 2 Reported age at seizure onset and anatomical and sex distribution in subependymal heterotopia

\begin{tabular}{|c|c|c|c|c|c|c|}
\hline \multirow[b]{2}{*}{ Authors } & \multicolumn{5}{|c|}{ Number of cases } & \multirow[b]{2}{*}{ Comments } \\
\hline & Total & Female/male & $\begin{array}{l}\text { Bilateral/ } \\
\text { unilateral }\end{array}$ & $\begin{array}{l}\text { No known } \\
\text { seizures }\end{array}$ & $\begin{array}{l}\text { Seizure onset } \\
\geqslant 10 \text { years }\end{array}$ & \\
\hline $\begin{array}{l}\text { Barkovich and } \mathrm{Kjos}^{8} \\
\text { DiMario et al } \\
\text { Hayden et al } \\
\text { Huttenlocher } \text { et } \text { al }^{15}\end{array}$ & $\begin{array}{l}8 \\
2 \\
1 \\
7\end{array}$ & $\begin{array}{l}6 / 2 \\
2 / 0 \\
1 / 0 \\
6 / 1\end{array}$ & $\begin{array}{l}7 / 1 \\
2 / 0 \\
0 / 1 \\
5+2 / 0 \dagger\end{array}$ & $\begin{array}{l}2 \\
0 \\
0 \\
2\end{array}$ & $\begin{array}{l}5 / 6 \\
2 / 2 \\
0 \\
3 / 5\end{array}$ & $\begin{array}{l}\text { Normal intelligence in six of eight patients } \\
\text { Report of a mother and daughter } \\
\text { CT only; seizure onset at age } 9 \text { years } \\
\text { Includes six patients from one family of four } \\
\text { generations }\end{array}$ \\
\hline Kernohan" & 1 & $1 / 0$ & $1 / 0$ & 0 & 0 & $\begin{array}{l}\text { Post-mortem diagnosis; patient died from } \\
\text { status epilepticus in infancy; additional } \\
\text { aqueductal stenosis }\end{array}$ \\
\hline $\begin{array}{l}\text { Palmini et al }{ }^{12} \\
\text { Palmini } \text { et al }^{7} \\
\text { Smith } \text { et } \text { al }^{13} \\
\text { Zisch and Artmann }{ }^{14} \\
\text { Current series }\end{array}$ & $\begin{array}{r}1 \\
1 \\
7 \\
2 \\
13\end{array}$ & $\begin{array}{r}1 / 0 \\
1 / 0 \\
? \\
? \\
12 / 1\end{array}$ & $\begin{array}{l}1 / 0 \\
1 / 0 \\
6 / 1 \\
1 / 1 \\
8 / 5\end{array}$ & $\begin{array}{l}0 \\
0 \\
1 \\
0 \\
0\end{array}$ & $\begin{array}{l}\quad ? \\
0 \\
6 / 6 \\
2 / 2 \\
9 / 13\end{array}$ & $\begin{array}{l}\text { Patient aged } 36 \text { years at evaluation } \\
\text { Seizure description suggests occipital onset } \\
\text { Sex of only two patients (1F, } 1 \mathrm{M}) \text { given } \\
\text { A third patient had associated pachygyria }\end{array}$ \\
\hline Total & 43 & $30 / 4^{\star \star \star}$ & $34 / 9$ & 5 & $27 / 34$ & \\
\hline
\end{tabular}

$\star \star \star<0.0001$.

tReported as bilateral in five, and presumed bilateral in two cases. 
may be due to direct damage to the fibres, deficiency of adhesion molecules necessary for the migration of neuroblasts along radial glial fibres, or premature transformation of the fibres into astrocytes. ${ }^{1720}$ The timing of this defect is probably late during the migration period-that is, nearer the 16th than the 7th gestational week, when most of the neurons have migrated to the cortical plate. Although most of our patients (eight of 13) had a history of prenatal or perinatal problems, these were generally mild, and the numbers are too small to make any inferences regarding aetiology. Palmini et $a l^{7}$ also postulated that in addition to the timing of events, the site (proximal) of the defect in the radial glial fibres and number of fibres involved may also be important factors in the pathogenesis of subependymal heterotopia. How prenatal and perinatal factors cause selective and not diffuse defects in the radial glial fibres remains unknown although focal subependymal infarcts or haemorrhages have been proposed. ${ }^{1}$

Subependymal heterotopia can be confidently diagnosed by neuroimaging. ${ }^{68913}$ Its anatomical delineation by $\mathrm{CT}$ is inferior to MRI. ${ }^{13}$ On CT, irregularities along the lateral walls of the lateral ventricles may be the only clue to the diagnosis of subependymal heterotopia. ${ }^{14}$ High resolution MRI can precisely delineate the morphology, distribution, and extent of subependymal heterotopia, and we have shown that subependymal heterotopia affects the trigones most often and frontal horns of the lateral ventricles least often. We have no explanation for this finding at present. In our experience, small nodules may require the use of thin section volumetric MRI to be adequately visualised (for example, patient 2).

The main differential diagnosis of subependymal heterotopia on neuroimaging is tuberous sclerosis. The salient features that differentiate the nodules of subependymal heterotopia from the hamartomas of tuberous sclerosis have been outlined by Barkovich et $a l^{6}$ and include their ovoid and smooth rather than elongated and irregular shape, isointensity to grey matter rather than isointensity or hypointensity to white matter, and lack of enhancement after gadolinium injection. Also, the lack of calcification of the nodules on CT would favour subependymal heterotopia rather than tuberous sclerosis. ${ }^{13}$ Moreover, none of our patients had a family history or stigmata of tuberous sclerosis.

The predilection of subependymal heterotopia for the right cerebral hemisphere is intriguing and has not been previously highlighted. One explanation may be that the right sided neuroblasts complete migration slightly later than those on the left.

Seizure onset in our series was typically in the second decade (nine of 13 patients) and this is the finding of other authors as well (table 2). The seizure pattern associated with subependymal heterotopia is variable.$^{814}$ Both partial as well as generalised epilepsy have been reported, and in our series, do not seem to be dictated by the distribution and size of the subependymal heterotopias. In fact, whether subependymal heterotopias are aetiological or just a marker of a more widespread developmental abnormality has been raised by some authors. ${ }^{13}$ Moreover, it has been diagnosed in patients without epilepsy (table 2). Indeed, the fact that the two patients with concomitant hippocampal sclerosis in our series have become seizure free or considerably improved after standard temporal lobectomy questions the relevance of some, if not all subependymal heterotopias, in epilepsy. To date, we have not been able to find reports of surgical resection of subependymal heterotopia for the control of epilepsy in the English literature. Morrell et al ${ }^{21}$ have demonstrated, however, with the use of intracerebral recordings, that subcortical laminar heterotopic grey matter can generate its own epileptic activity, thus supporting intrinsic epileptogenicity of heterotopic grey matter, although we are not aware of the use of a similar technique in patients with subependymal heterotopia. Although most of our patients have had severe epilepsy from childhood or adolescence, this may reflect patient selection bias, and the frequency of subependymal heterotopia in patients with mild or later onset epilepsy is not known.

The most likely explanation for the variability in the epileptogenicity of subependymal heterotopia, which probably also applies to other cortical dysgeneses, is that some other factor or insult, probably in postnatal life, is sometimes necessary to trigger the epilepsy. The relation of hippocampal sclerosis to cortical dysgenesis is beyond the scope of this paper but it will be interesting to see if our two patients with concomitant hippocampal sclerosis remain seizure free during subsequent follow up. Despite these controversies, it is our belief that subependymal heterotopia is epileptogenic in all our patients.

Three patients in our series showed 3 or 4 per second generalised spike and wave activity. Whether this is concomitant primary generalised epilepsy or due to the subependymal heterotopia is unresolved. Clinically, only one of these patients (patient 7) had absences suggestive of primary generalised epilepsy but her attacks have been medically refractory despite adequate doses of sodium valproate, ethosuximide, and phenytoin. The onset of epilepsy in the second decade, the negative family history for epilepsy, the absence of early morning myoclonic jerks, and lack of photosensitivity, are all further points against the diagnosis of primary generalised epilepsy in any case. ${ }^{22}$ The possibility then exists, that there may be some patients, particularly females, who have an EEG diagnosis of, and masquerade as primary generalised epilepsy, who have subependymal heterotopia. The possible relation of this finding to the suggestion that microdysgenesis may be the pathological basis of primary generalised epilepsy in some cases $^{23}$ is also intriguing.

A female predominance has been reported in bilateral band heterotopia ("double cortex 
syndrome") ${ }^{1819}$ and Aicardi syndrome. ${ }^{24}$ Subependymal heterotopia would be the third neuronal migration disorder associated with a female predominance. A review of the English medical literature of cases of "pure" subependymal heterotopia also shows a female predominance (table 2). When these cases are combined with our cases, there is a total of 30 female and four male patients. This female predominance was statistically significant $(\mathrm{p}<0.0001)$. Subependymal heterotopia that is associated with other cerebral abnormalities (for example, agenesis of the corpus callosum and other cortical dysgeneses) does not seem to be associated with a sex predominance, but seems to be associated with mental retardation and a poor prognosis. ${ }^{25-28}$ The term "pure subependymal heterotopia" has been used with caution because the diagnosis in all previous reports except one, ${ }^{11}$ included in this analysis were based on neuroimaging. As illustrated by our patient with microdysgenesis and splitting of the dentate fascia, not all cortical dysgeneses will be detected by neuroimaging. And, it is possible that some of the patients in our and previous reports might have abnormalities beyond the resolution of neuroimaging.

The reason for the female predominance is unclear, but an $\mathrm{X}$ linked dominant inheritance with prenatal lethality in hemizygous males, a mechanism proposed for Aicardi syndrome, ${ }^{29}{ }^{30}$ has been suggested for some cases: Huttenlocher et al ${ }^{15}$ recently reported six members of a family (all of whom were females) with subependymal heterotopia; multiple spontaneous abortions and a deficiency of male offsprings strongly suggested $\mathrm{X}$ linked dominant inheritance with prenatal male lethality. Four out of nine of our probands had male siblings. This does not exclude an $\mathrm{X}$ linked dominant inheritance because there is still a $25 \%$ chance of a healthy male being born. Because well documented male cases exist, however, there must be sporadic forms of the condition or alternative as yet unrecognised factors.

The female predominance in subependymal heterotopia and bilateral band heterotopia is striking and would lend support to the role of the $\mathrm{X}$ chromosome in cerebral development.

In conclusion, subependymal heterotopia is clearly distinct from other neuronal migration disorders: females are predominantly affected, age at seizure onset is usually in the second decade, and intelligence is often normal or only mildly compromised. And, in the presence of preserved intellectual function, some patients whose EEGs show normal background activity and $3-\mathrm{Hz}$ or $4-\mathrm{Hz}$ spike and wave activity may masquerade as primary generalised epilepsy. Subependymal heterotopia is more often bilateral than unilateral, most commonly affects the occipital horns of the lateral ventricles, and affects the right more than the left cerebral hemisphere. Further studies are required to investigate the interaction of genetic and perinatal factors in the pathogenesis of subependymal hetero- topia, and the prevalence of asymptomatic and familial cases.

1 Sarnat HB. Cerebral dysplasias as expressions of altered maturational processes. Can $\mathcal{f}$ Neurol Sci 1991;18 196-204.

2 Angevine JB Jr, Sidman RL. Autoradiographic study of cell migration during histogenesis of cerebral cortex in the mouse. Nature 1961;192:766-8.

3 Rakic $P$. Neuronal migration and contact guidance in the primate telencephalon. Postgrad Med $\mathcal{F} 1978$ (suppl);54: 25-40.

4 Walsh C, Cepko CL. Clonal dispersion in proliferative layers of developing cerebral cortex. Nature 1993;362: layers of

5 Barth PG. Disorders of neuronal migration. Can $\mathcal{F}$ Neurol Sci 1987;14:1-16.

6 Barkovich AJ, Gressens P, Evrard P. Formation, maturation, and disorders of brain neocortex. AfNR $A m \mathfrak{F}$
torkich Neuroradiol 1992;13:423-46.

7 Palmini A, Andermann F, de Grissac $\mathrm{H}$, et al. Stages and patterns of centrifugal arrest of diffuse neuronal migration disorders. Dev Med Child Neurol 1993;35 331-9.

8 Barkovich AJ, Kjos BO. Gray matter heterotopias: MR characteristics and correlation with developmental and neurologic manifestations. Radiology 1992;182:493-9.

9 DiMario FJ, Cobb RJ, Ramsby GR, Leicher C. Familial band heterotopias simulating tuberous sclerosis. Neurology 1993;43:1424-6.

10 Hayden SA, Davis KA, Stears JC, Cole M. MR imaging of heterotopic grey matter. Fournal of Computer Assisted Tomography 1987;11:878-9.

11 Kernohan JW. Cortical anomalies, ventricular heterotopias and occlusion of the aqueduct of Sylvius. Archives of and occlusion of the aqueduct of Sylvius.
Neurology and Psychiatry 1930;23:460-80.

12 Palmini A, Andermann F, Olivier A, et al. Neuronal migration disorders: a contribution of modern neuroimaging to the etiologic diagnosis of epilepsy. Can $\mathcal{F}$ Neurol Sci 1991;18:580-7.

13 Smith AS, Weinstein MA, Quencer RM. Association of heterotopic grey matter with seizures: MR imaging. Radiology 1988;168:195-8.

14 Zisch R, Artmann W. MR in the diagnosis of heterotopic grey matter. Neuroradiology 1991;33:527-8.

15 Huttenlocher PR, Taravath S, Mojtahedi S. Periventricular heterotopia and epilepsy. Neurology 1994; 44:51-5.

16 Cook MJ, Fish DR, Shorvon SD, Straughan K, Stevens JM. Hippocannpal volumetric and morphometric studies in frontal and temporal lobe epilepsy. Brain 1992;15: in frontal

17 Meencke HJ, Veith G. Migration disturbances in epilepsy. In: Engel J Jr, Wasterlain C, Heinemann U, Avanzini G eds. Molecular neurobiology of epilepsy. Amsterdam Elsevier, 1992:31-40.

18 Barkovich AJ, Jackson DE Jr, Boyer RS. Band heterotopias: a newly recognised neuronal migration anomaly. Radiology 1989;171:455-8.

19 Palmini A, Andermann F, Aicardi J, et al. Diffuse cortical dysplasia, or the 'double cortex' syndrome: the clinical and epileptic spectrum in 10 patients. Neurology 1991 41:1656-62.

20 Barkovich AJ, Chuang SH, Norman D. MR of neuronal migration anomalies. AfNR Am $\mathcal{f}$ Neuroradiol 1987;8: 1007-17.

21 Morrell F, Whistler WW, Hoeppner TJ, et al. Electrophysiology of heterotopic gray matter in the 'douElectrophysiology of heterotopic gray matter in the 'd
ble cortex' syndrome. Epilepsia 1992;33(suppl 3):76.

22 Niedermeyer E. Epileptic seizure disorders. In: Niedermeyer E, Da Silva FL, eds. Electro-
Niedermeyer E. Epileptic seizure disorders. In: encephalography: basic principles, clinical applications, and related fields. Baltimore: Williams and Wilkins, 1993: 461-564.

23 Meencke HJ, Janz D. The significance of microdysgenesia in primary generalized epilepsy: an answer to the considerations of Lyon and Gastaut. Epilepsia 1985;26: 368-71.

24 Aicardi J, Lefebvre J, Lerique-Koechlin A. A new syndrome: spasm in flexion, callosal agenesis, ocular abnormalities. Electroencephalogr Clin Neurophysiol 1965;19: 609-10.

25 Bergeron RT. Radiographic demonstration of cortical heterotopia. Acta Radiol 1969;9:135-9.

26 Mueller CF. Heterotopic grey matter. Radiology 1970;94: 357-8.

27 Bairamian D, Di Chiro G, Theodore WH, Holmes MD, Dorwart RH, Larson SM. MR imaging and positron emission tomography of cortical heterotopia. fournal of Computer Assisted Tomography 1985;9:1137-9.

28 Yasumori K, Hasuo K, Nagata S, Masuda K, Fukui M Neuronal migration anomalies causing extensive ventricular indentation. Neurosurgery 1990;26:504-7.

29 Pembrey ME. Genetic factors in disease. In: Weatherall DJ, Ledingham JGG, Warrell DA, eds. Oxford textbook of medicine. Oxford: Oxford University Press, 1987:4.1$\mathbf{4 \cdot 4 0 .}$.

30 Carter CO. Sex-linkage and sex-limitation. In: Ounsted C, Taylor DC, eds. Gender differences: their ontogeny and significance. Edinburgh: Churchill Livingstone, 1972: $1-12$. 